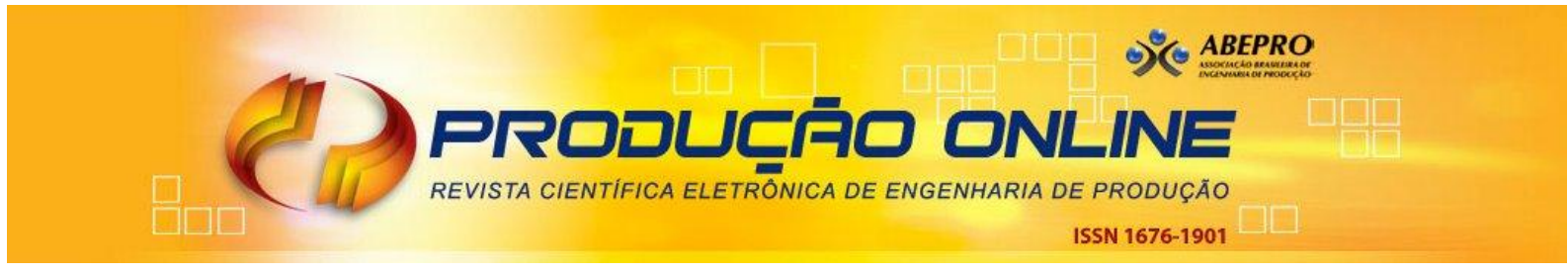

\title{
MAPEAMENTO DO FLUXO DE VALOR EM UM MODELO DE SIMULAÇÃO COMPUTACIONAL
}

\section{VALUE STREAM MAPPING IN A COMPUTATIONAL SIMULATION MODEL}

\author{
Ricardo Becker Mendes de Oliveira* E-mail: prof becker@yahoo.com.br \\ Valesca Alves Corrêa* E-mail: valesca.correa@unitau.com.br \\ Luiz Eduardo Nicolini do Patrocínio Nunes* E-mail: luiz@unitau.br \\ Universidade de Taubaté (UNITAU), Taubaté, SP
}

\begin{abstract}
Resumo: O processo decisório nas empresas tem sido objeto de estudo de diversos pesquisadores e executivos e muito tem sido explorado e analisado sobre o tema. Este trabalho tem como objetivo utilizar a metodologia de Mapeamento do Fluxo de Valor (MFV) de modo integrado a um modelo de simulação computacional, construído com o software ARENA, para ampliar a visão do gestor na tomada de decisão. $O$ objeto de estudo está baseado em um sistema produtivo que envolve um processo de embalamento automático de produtos, onde surgiu a necessidade de realizar modificações no atual sistema visando para acomodar novos produtos e para isso, devem-se detectar os possíveis gargalos e visualizar os impactos gerados pelas futuras modificações. A simulação visa a colaborar na tomada de decisão do gestor considerando que o sistema envolve diversas variáveis e seus comportamentos definem a complexidade do processo. Como resultados será apresentado o modelo de simulação computacional qualificado para representar o sistema atual e o futuro, com redução significativa dos custos de projeto por antecipar seu comportamento; em conjunto com os resultados do Mapeamento do Fluxo de Valor para identificar as atividades que agregam valor ou não para o processo. A validação do modelo de simulação ocorrerá com o mapa atual do sistema e com a inclusão de eventos Kaizen para que no mapa futuro, os desperdícios sejam encontrados de forma mais prática e confiável, auxiliando na tomada de decisão.
\end{abstract}

Palavras-chave: Mapeamento do Fluxo de Valor. Modelo de Simulação Computacional. Pensamento Enxuto. Tomada de Decisão. Kaizen.

\begin{abstract}
The decision-making process has been extensively studied by researchers and executives. This paper aims to use the methodology of Value Stream Mapping (VSM) in an integrated manner with a computer simulation model, in order to expand managers decision-making vision. The object of study is based on a production system that involves a process of automatic packaging of products, where it became necessary to implement changes in order to accommodate new products, so that the detection of bottlenecks and the visualization of impacts generated by future modifications are necessary. The simulation aims to support manager's decision considering that the system involves several variables and their behaviors define the complexity of the process. Significant reduction in project costs by anticipating their behavior, together with the results of the Value Stream Mapping to identify activities that add value or not for the process were the main results. The validation of the simulation model will occur with the current map of the system and with the inclusion of Kaizen events so that waste in future maps are found in a practical and reliable way, which could support decision-makings.
\end{abstract}

Keywords: Value Stream Mapping. Computer Simulation Model. Lean Thinking. Decision Making. Kaizen. 


\section{INTRODUÇÃO}

Atualmente, as organizações buscam a vantagem competitiva para se manter ativas e atualizadas no mercado. Por isso, a crescente importância de se tentar entender e construir modelos que tragam uma melhor aplicabilidade de técnicas e regras em um processo de tomada de decisão empresarial, onde a informação se mostra um recurso fundamental para as novas tendências mundiais. O Pensamento Enxuto aparece nesse conceito e vem ajudando diversas empresas na busca deste diferencial e é descrito em alta gama de bibliografias com sucesso em sua aplicação em indústrias de transformação e beneficiamento.

Para que um determinado projeto de negócios possa ser avaliado, seus resultados devem ser antecipados e considerados de acordo com as possíveis mudanças no ambiente. $O$ uso de modelos mentais e de cenários dinâmicos computacionais, durante o processo de planejamento, visa criar novas fontes de informação que sensibilizem os gestores e planejadores para as implicações de suas decisões sobre a organização (FIGUEIREDO, 2009).

Segundo Choo (2003) as decisões resultam da adoção de um curso de ação, e facilitam esta ação na medida em que definem e elaboram propósitos, alocam recursos e autorizam sua execução, portanto, o processo decisório pode ser visto como um conjunto de ações e fatores que têm início a partir da identificação de um estímulo para a ação e que se finaliza com a alocação do recurso específico para a ação.

Pegden et al. (1995) determina a simulação como uma metodologia experimental que é aplicável a diversos sistemas e tem como premissas: descrever o comportamento de sistemas, a construção de teorias ou hipóteses que explicam o comportamento observado, o uso do modelo de simulação computacional para prever um comportamento futuro, isto é, efeitos produzidos por mudanças no sistema ou forma de operá-lo. Ela permite prever o comportamento de processos de forma que os custos sejam reduzidos ao somente o necessário e o projeto de atender à sua demanda de forma eficaz.

O objetivo deste trabalho é utilizar a ferramenta de Mapeamento do Fluxo de Valor (MFV) proveniente do conceito da filosofia Lean em conjunto com o software Arena para construir um modelo de simulação computacional pela realização do 
mapa atual, que possa apontar os desperdícios ocorrentes na produção e um mapa futuro para poder quantificar as possíveis melhorias visando demonstrar os gargalos do processo produtivo e auxiliar desta forma a tomada de decisão quanto à inclusão da produção de novos produtos.

\section{FUNDAMENTAÇÃO TEÓRICA}

\subsection{Tomada de Decisões}

Dos elementos que compõem o processo de tomadas de decisão, alguns deles influenciam de forma direta na escolha dos administradores e trazem consequências para os demais. Os objetivos, o estado da natureza e a situação irão determinar as possíveis alternativas para a escolha da estratégia que melhor definirá a tomada de decisão. E, por fim, os resultados serão consequências da estratégia estabelecida para alcançá-los (CHIAVENATO, 2004).

Segundo Harrison (1993) o processo de tomada de decisão é um produto de uma cultura onde a decisão acontece e, ao mesmo tempo, influencia essa cultura. Afirma também que o processo decisório, em um universo mutável e complexo, leva em conta relevantes aspectos de muitas disciplinas, não só da economia, da matemática e da estatística. Um modelo de tomada de decisão mostra, graficamente, qual a ênfase que as disciplinas em pauta devem receber no processo de tomada de decisão, e deve incluir um número 'ideal' de variáveis que irão expor os fenômenos do sistema de forma mais simplificada.

\subsection{Filosofia Lean}

A produção enxuta é uma filosofia que engloba diferentes práticas gerenciais, como: Just in Time (JIT), Sistema da Qualidade Total (SQT), trabalho em equipe, layout celular e Mapeamento de Fluxo de Valor (MFV). Foca na identificação e eliminação de desperdícios por toda cadeia de valor e, para que essas práticas possam trabalhar sinergicamente fabricando produtos com qualidade esperada pelo cliente acompanhando a demanda (CRUTE et al., 2003; SCHERRER-RATHJE; BOYLE; DEFLORIN, 2009; SHAH; WARD, 2003 apud GAMBI, 2011). Algumas empresas como Dupont e Bosch têm aplicado os conceitos do Lean Thinking ou 
Pensamento Enxuto, também fora do chão de fábrica e colhendo ótimos resultados (LEAN SUMMIT, 2004).

Ohno (1997) aponta a origem da filosofia Lean no Sistema Toyota de Produção e seu objetivo principal é trabalhar para atender os clientes no menor tempo possível, na mais alta qualidade perceptível pelo cliente e com o menor custo possível.

Womack e Jones (1996) afirmam que o pensamento enxuto traz redução de desperdícios e melhora a eficiência da organização. Faz-se necessário criar um ciclo de melhoria contínua como uma forma de especificar valor, alinhar na melhor sequência as ações que criam valor, realizar essas atividades sem interrupção e considerar o conjunto inteiro de atividades na criação e fabricação de um produto, na execução de um serviço e fluxo de informações.

Hines e Taylor (2000) demonstram quais são as ferramentas e para qual tipo de desperdícios estas são mais indicadas e expõem a capacidade de detalhamento de cada tipo de desperdício por ferramenta. O Quadro 1 classifica esta capacidade como: ferramenta adequada (sim), ferramenta não adequada (não) e ferramenta mais ou menos adequada (mais ou menos).

Quadro 1- Ferramentas da Produção Enxuta.

\begin{tabular}{|c|c|c|c|c|c|c|}
\hline & & & Ferran & entas & & \\
\hline s & $\begin{array}{l}\text { Mapeamento } \\
\text { de Atividade } \\
\text { do Processo }\end{array}$ & $\begin{array}{c}\text { Matriz de } \\
\text { Resposta da } \\
\text { Cadeia de } \\
\text { Suprimentos }\end{array}$ & $\begin{array}{c}\text { Funil de } \\
\text { Variedade de } \\
\text { Produção }\end{array}$ & $\begin{array}{c}\text { Mapa de } \\
\text { filtro de } \\
\text { Qualidade }\end{array}$ & $\begin{array}{c}\text { Mapa de } \\
\text { Amplificação } \\
\text { de Demanda }\end{array}$ & $\begin{array}{l}\text { Perfil de } \\
\text { Tempo de } \\
\text { Valor } \\
\text { Agregado }\end{array}$ \\
\hline Superprodução & $\begin{array}{l}\text { mais ou } \\
\text { menos }\end{array}$ & $\begin{array}{l}\text { mais ou } \\
\text { menos }\end{array}$ & não & $\begin{array}{l}\text { mais ou } \\
\text { menos }\end{array}$ & $\begin{array}{l}\text { mais ou } \\
\text { menos }\end{array}$ & sim \\
\hline Defeitos & $\begin{array}{l}\text { mais ou } \\
\text { menos }\end{array}$ & não & não & $\operatorname{sim}$ & não & $\begin{array}{l}\text { mais ou } \\
\text { menos }\end{array}$ \\
\hline $\begin{array}{c}\text { Inventário } \\
\text { Desnecessário }\end{array}$ & $\begin{array}{l}\text { mais ou } \\
\text { menos }\end{array}$ & sim & $\begin{array}{l}\text { mais ou } \\
\text { menos }\end{array}$ & não & sim & $\begin{array}{l}\text { mais ou } \\
\text { menos }\end{array}$ \\
\hline $\begin{array}{c}\text { Processo } \\
\text { Inadequado }\end{array}$ & $\operatorname{sim}$ & não & $\begin{array}{l}\text { mais ou } \\
\text { menos }\end{array}$ & $\begin{array}{l}\text { mais ou } \\
\text { menos }\end{array}$ & não & $\begin{array}{l}\text { mais ou } \\
\text { menos }\end{array}$ \\
\hline $\begin{array}{l}\text { Transporte } \\
\text { Excessivo }\end{array}$ & $\operatorname{sim}$ & não & não & não & não & $\operatorname{sim}$ \\
\hline Esperas & $\operatorname{sim}$ & $\operatorname{sim}$ & $\begin{array}{l}\text { mais ou } \\
\text { menos }\end{array}$ & não & $\begin{array}{l}\text { mais ou } \\
\text { menos }\end{array}$ & $\begin{array}{l}\text { mais ou } \\
\text { menos }\end{array}$ \\
\hline $\begin{array}{l}\text { Movimentação } \\
\text { Desnecessária }\end{array}$ & $\operatorname{sim}$ & $\begin{array}{l}\text { mais ou } \\
\text { menos }\end{array}$ & não & não & não & não \\
\hline
\end{tabular}

Fonte: Peter Hines \& David Taylor, 2000.

Revista Produção Online, Florianópolis, SC, v.14, n. 3, p. 837-861, jul./set. 2014. 
O Mapeamento do Fluxo de Valor é uma ferramenta que está na base dos pilares do pensamento enxuto que facilita a visualização e o entendimento do fluxo de materiais e informações, e identifica quais os fluxos que estão agregando valor ao processo. Permite a identificação dos desperdícios que ocorrem por toda a cadeia mapeada, além de um suporte à tomada de decisão e forma a base para um plano de oportunidades e melhorias. Mapear o fluxo de valor pode representar uma ferramenta informal de comunicação, de planejamento de negócios e um instrumento valioso para gerenciar o processo de mudança, cuja função estratégica é a de estruturar toda a implementação da metodologia do pensamento enxuto. $O$ mapeamento do fluxo de valor segue as seguintes etapas: desenho do estado atual, desenho do estado futuro e plano de trabalho (ROTHER e SHOOK, 1999). A Figura 1 mostra a representação do esquema de fluxo de valor.

O mapeamento do fluxo de valor utiliza um conjunto padronizado de símbolos e necessita que todos os envolvidos estejam alinhados com os objetivos do projeto e compreendam os conceitos dos mapas do MFV e sua simbologia.

Figura 1 - Representação do esquema do Fluxo de Valor.

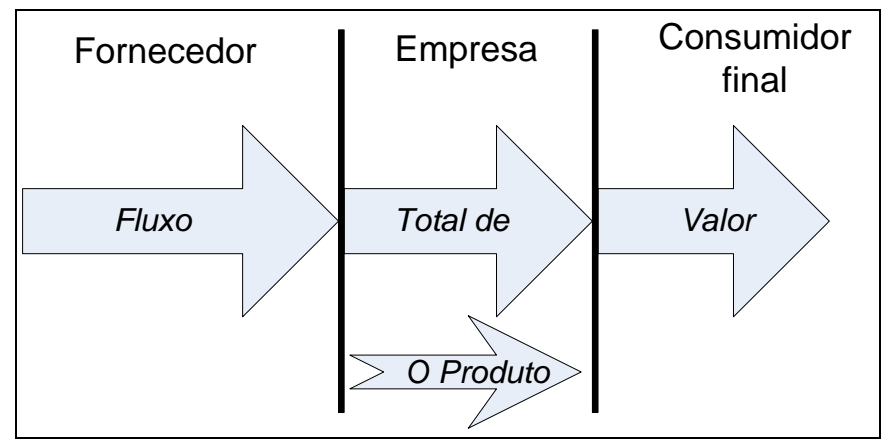

Fonte: Rother e Shook (1999)

\subsection{Simulação Computacional}

A simulação segundo Pegden et al. (1995), é o processo de projetar um modelo computacional de um sistema real e conduzir experimentos com este modelo objetivando o entendimento de seu comportamento e/ou avaliar estratégias para sua operação.

As indústrias de manufatura sempre foram as maiores usuárias da simulação, sendo a simulação de eventos discretos uma das mais poderosas Revista Produção Online, Florianópolis, SC, v.14, n. 3, p. 837-861, jul./set. 2014. 
ferramentas para modelagem e análise de problemas, utilizada para o planejamento, projeto e controle de sistemas complexos, assim como manufatura, sistemas de manuseio de materiais, engenharia civil, indústria automobilística, transporte, área militar, sistemas de comunicação, sistemas de planejamento e vários sistemas com forte estrutura em filas (HARREL et al.,1997 apud SILVA, 2006).

A simulação é uma técnica utilizada para analisar problemas cuja solução analítica é impraticável, seja pela presença de variáveis aleatórias ou por excessiva complexidade do sistema (PINTO, 2007). Um dos modos de reduzir custos no planejamento é utilizar a técnica de simular o sistema a ser estudando a fim de prever as diversidades e viabilidade técnica e econômica. Freitas (2008) define a simulação como forma de imitar praticamente qualquer operação de um processo ou sistema do mundo real utilizando técnicas matemáticas.

A construção do modelo de simulação computacional pode ser um trabalho minucioso, entretanto, uma vez concluído, pode ser usado para simular períodos de tempo arbitrários em uma pequena fração do tempo real, viabilizando um grande número de experimentos; além disso, um modelo de simulação pode ser replicado quantas vezes forem necessárias para garantir uma tomada de decisão mais segura e se basear em resultados confiáveis (PIDD, 1992 apud QUEVEDO, 2009).

Os modelos de simulação podem ser híbridos, contendo mais de uma classificação ativa dentro de sua lógica (nome dado para definir o comportamento de um processo, maquina ou uma situação programada dentro do simulador). Podemse criar cenários que contemplam a logística de materiais e informações bem como previsão de defeitos e comportamentos aleatórios. A Figura 2 mostra uma representação das diversas propostas de técnicas de simulação quanto à flexibilidade. 
Figura 2 - Prós e contras na escolha da ferramenta utilizada na modelagem.

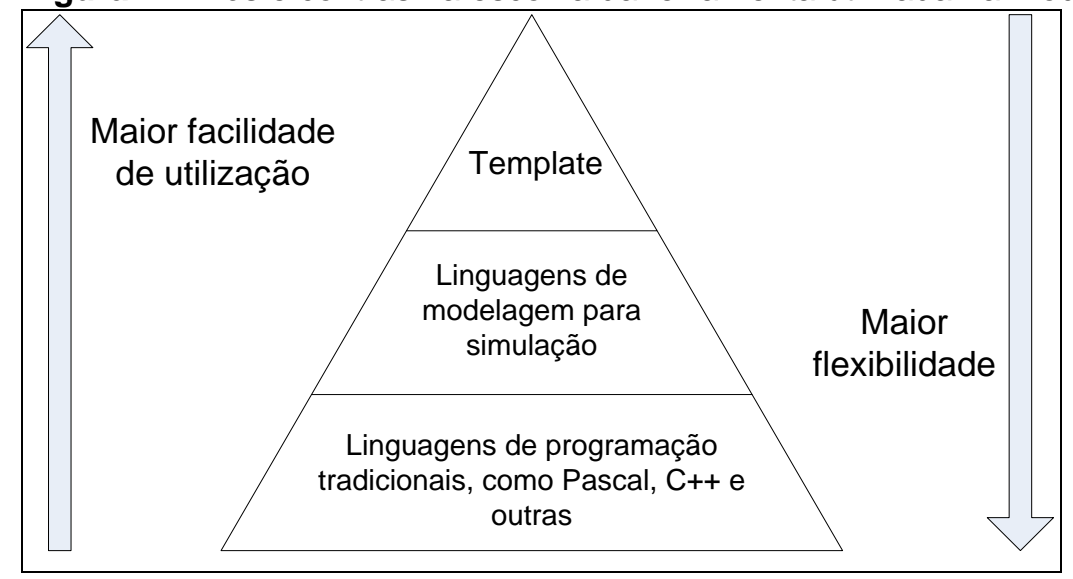

Fonte: Adaptado de (FIORONI, 2008).

As principais informações do modelo simulado neste trabalho estão armazenadas em variáveis que são definidas por Kelton e Sadowski (1998) como elementos que guardam informações globais e que podem registrar grande quantidade de informações do sistema. As variáveis podem ser usadas para registrar a quantidade de entidades dentro do sistema ou o estado de um determinado elemento do sistema (como por exemplo, indisponibilidade de um comércio devido ao horário de atendimento). As variáveis podem conter informações simples, bem como armazenar grande quantidade de informações quando utilizada como vetor ou matriz.

Segundo Martins (2009), variáveis indexadas são arranjos multidimensionais para o armazenamento de dados e as funções são procedimentos de código prédefinidos para a modularização e organização dos códigos em programas.

A elaboração de bons projetos para implantação de novas tecnologias é de fundamental importância para que uma empresa se mantenha competitiva frente a seus concorrentes (GONÇALVES et al, 2011).

\subsection{Simulação em conjunto com o MFV}

Em algumas situações, por ser naturalmente estático, o mapa do estado futuro do MFV não consegue expor detalhes e pode mascarar resultados. Um exemplo seria a previsão e análise dos níveis de estoque em diversos momentos da produção, com diferentes parâmetros (MCDONALD. AKEN e RENTES. 2002). 
Para auxiliar uma organização a inserir técnicas enxutas e aprimoramento contínuo, uma ferramenta complementar para o mapeamento do fluxo de valor é necessária para quantificar os ganhos durante todas as etapas do planejamento. A simulação neste caso permite enxergar os detalhes, necessidades de recursos e estatísticas de desempenho, mantendo-se ainda flexível para diversas modificações pré e pós MFV da organização (DONATELLI; HARRIS, 2004).

A simulação computacional pode ser usada para reduzir a incerteza e criar exibições dinâmicas da situação futura do MFV, além de gerar mapas alternativos de acordo com diferentes cenários projetados. Isso permite aferir o retorno do uso do MFV e seu impacto sobre o sistema total. Algumas diferenças entre MFV e Simulação podem ser vistas na Figura 3 (SOLDING; GULLANDER 2009).

Figura 3 - Diferenças entre MFV e Simulação

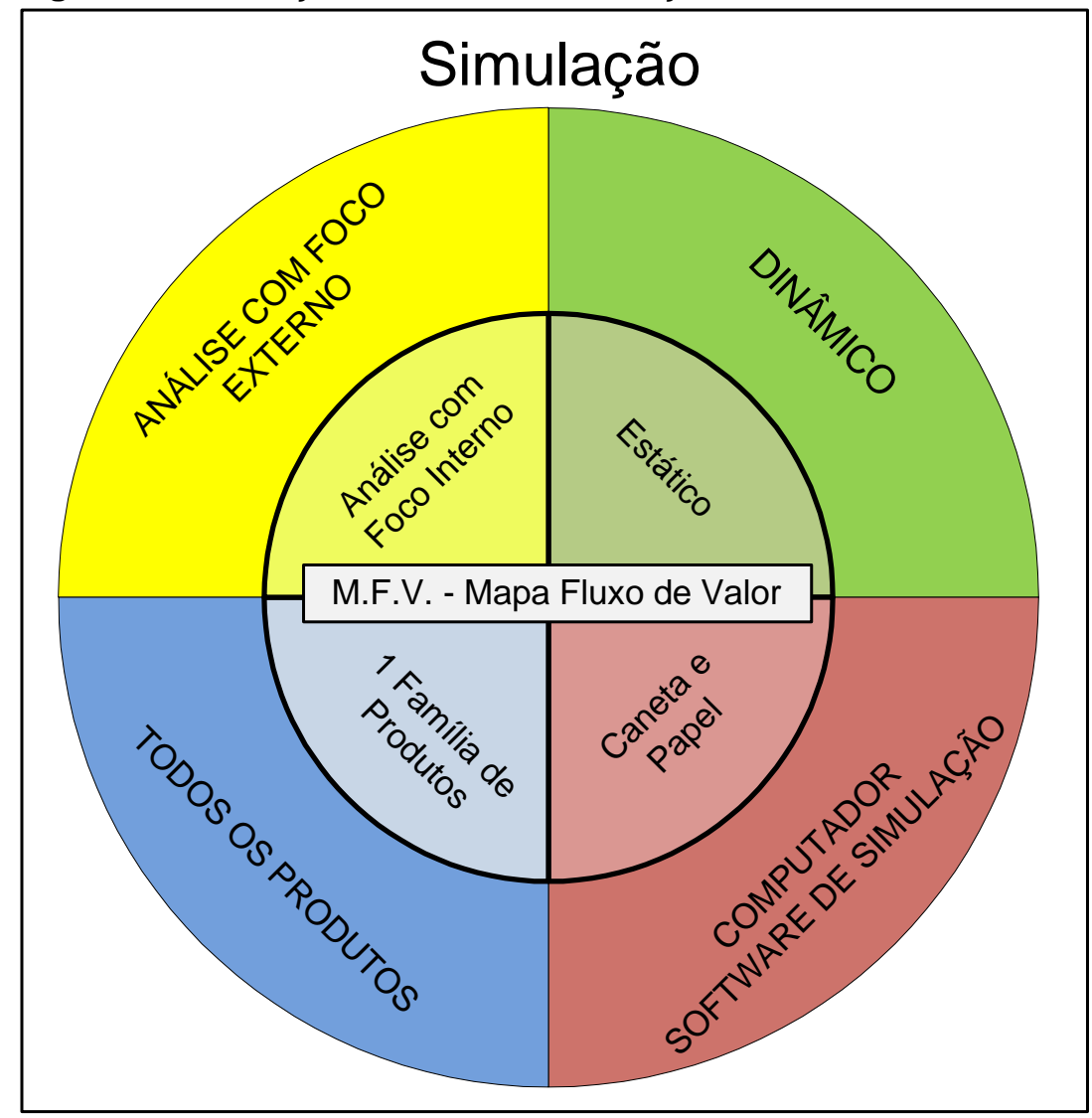

Fonte: Adaptado de Solding e Gullander, 2009.

Solding e Gullander (2009). Anand e Kodali (2009). Kurkin e Simon (2011) e muitos outros pesquisadores têm utilizado a simulação de eventos discretos em um ambiente de manufatura enxuta. 
Na Dissertação de Bekesas (2012) a simulação computacional foi utilizada com o software ProModel $\circledast$ em conjunto com o MFV em uma empresa do setor metal mecânico para avaliar os ganhos em utilizar a Simulação e os mapas em uma base interativa. O método que utilizou foi de coleta de dados por entrevistas e inspeção do processo, construiu o mapa de fluxo de valor atual e futuro no software Microsoft Visio $\AA$, e posteriormente uma simulação integrada com o mapa futuro. A simulação em uma base interativa acrescentou a dimensão de tempo para o MFV, tornando fácil saber o estado do sistema diversas circunstâncias, proporcionado uma tomada de decisão mais precisa com maior segurança.

No entanto, Bekesas (2012) afirma que na literatura ainda há pouca literatura sobre o uso de simulação para complementar mapeamento do fluxo de valor. McDonald. Van Aken e Rentes (2002) utilizaram a simulação computacional em um sistema de controle de movimentos de alto desempenho para manufatura e demonstraram que a simulação pode ser uma ferramenta importante na avaliação de diferentes mapas de estado futuro. Eles concluíram que a simulação pode fornecer e analisar cenários diferentes para complementar aqueles obtidos a partir de mapeamento do estado futuro.

\section{FORMULAÇAO DO PROBLEMA}

O estudo de caso está baseado em um sistema de produção com processo de embalamento automático e diversidade de insumos. Por motivos de confidencialidade, o sistema de produção não será exposto em detalhes, o mesmo acontece com o tipo de produto final, detalhes de máquinas e nome da empresa.

A Empresa apresentava um problema na tomada de decisões sobre as melhorias que poderiam ser implementadas e seus reais impactos. As melhorias veem da necessidade de realizar modificações em seu sistema para acomodar novos produtos, visualizar os gargalos atuais e os impactos gerados pelas futuras modificações, bem como o comportamento do sistema trabalhando com todas as variáveis do processo. Devido a variedade de dados simultâneos envolvidos, seria inviável implementar de forma precisa todas as variantes e combinações de máquinas para saber quais as modificações que seriam necessárias para que 0 sistema se comportasse de forma mais eficiente. Considerando a complexidade do 
problema para a tomada de decisão estratégica e operacional, um modelo de simulação computacional foi requerido.

O processo de fabricação consiste em um fluxo continuo de abastecimento de matéria prima, dividido em três turnos e com estoque intermediário entre setores que garantem o balanceamento da linha. Há dois insumos principais que compõem a fabricação do produto e a chegada destes materiais são programadas para alimentar um estoque mínimo. A matéria prima é dividida em dois lotes distintos que compõe este estoque mínimo e a regra de consumo obedece a um processo do tipo FIFO First In First Out. O estoque de matéria prima tem este comportamento porque o produto é de alta rotatividade, perecível e consequentemente, deteriora e perde seu valor rapidamente se não for consumido em um determinado período de tempo.

O processo de chegada de material, estocagem e transporte até o inicio da produção não é relevante e não interfere neste estudo, bem como para o modelo de simulação computacional. O planejamento e programação da produção são feitos de forma manual e se concentra em três setores principais, o de mistura, movimentação com silos móveis e embalamento. O estudo tem foco no planejamento e programação da produção onde a empresa sempre encontrou dificuldades para balancear e controlar a linha de produção.

Devido à grande quantidade de variáveis do processo produtivo relevantes na análise dos eventos, o modelo que será utilizado neste trabalho foi desenvolvido através de um método determinístico de Simulação Computacional que permite simular o processo de forma que se assemelhe ao funcionamento deste sistema em particular. Por isso a empresa recorreu à simulação computacional para viabilizar os testes e prever com precisão a resposta do sistema. A proposta de aliar os mapas MFV com a simulação surgiu durante o desenvolvimento do modelo de simulação como uma nova abordagem deste conceito.

\section{DESENVOLVIMENTO}

Segundo Freitas (2008), na maioria dos problemas envolvendo simulação de sistemas, a coleta de dados é uma tarefa difícil e demorada. Em geral, há duas situações possíveis: a existência ou a possibilidade de obtenção de dados e a não existência e impossibilidade de obtenção de dados. No caso deste trabalho os dados 
foram coletados de acordo com apontamentos do processo real e histórico de operações.

O uso do conceito de lógica indexada permite que grandes quantidades de informações sejam armazenadas em uma única variável e este trabalho utiliza este conceito com a finalidade de simplificar a modelagem, ampliar a flexibilidade do usuário para modificar informações e obter melhor controle de resultados.

O processo exigiu uma modelagem bem flexível, contemplando mudanças nas características individuais das máquinas e futuras ampliações em cada cenário, como:

- Aumento e/ou diminuição de todas as máquinas utilizadas no sistema;

- Modificação do comportamento de alguns processos de acordo com o plano de melhorias Kaizen (melhoria contínua) e como isso afeta a produção;

- Apontar os gargalos da produção de acordo com as mudanças;

- Controle do usuário para modificar os parâmetros de cada máquina individualmente.

Os dados de entrada podem ser modificados, juntamente com a quantidade de máquinas disponíveis e número de operadores. A possibilidade de construção de diversos cenários permite o estudo minucioso de cada etapa da produção, aponta as limitações atuais e futuras que poderão afetar a capacidade de abastecimento de produto nas máquinas de embalagem.

O modelo de simulação é composto pela "Interface" e pelo "Modelo" que permitem ao usuário desenvolver simulações e análises baseadas no modelo desenvolvido no software Arena. Todas as variáveis do modelo são preenchidas manualmente em uma planilha do software Microsoft Excel que interagem com o modelo de simulação. Os resultados também são exportados para este arquivo que pode ser visualizado após a conclusão do cenário simulado.

O padrão de variáveis elaborado no Microsoft Excel é mostrado na Figura 4 e representa as máquinas, equipamentos e demais dados do processo que foram construídas para serem exportadas para o software Arena. O objetivo de construir estes dados em planilhas é controlar todos os parâmetros do modelo, permitir alterações pelo usuário dos parâmetros de cada cenário e usar as matrizes das planilhas como gabaritos para alimentar o modelo no software Arena.

Revista Produção Online, Florianópolis, SC, v.14, n. 3, p. 837-861, jul./set. 2014. 
Figura 4 - Planilha de construção da variável indexada para alimentar os dados de entrada no modelo de simulação

\begin{tabular}{|c|c|c|c|c|c|c|c|c|c|}
\hline & A & B & C & D & $E$ & $\mathrm{~F}$ & G & $\mathrm{H}$ & 1 \\
\hline $\begin{array}{l}16 \\
17\end{array}$ & & & 1 & 2 & 3 & 4 & & 6 & 7 \\
\hline 18 & & v_maquina & Maquina Ativa? & $\begin{array}{l}\text { Ultimo produto na } \\
\text { Maquina }\end{array}$ & \begin{tabular}{|c|} 
Taxa de produçẫo \\
Pratica (kglmin)
\end{tabular} & $\begin{array}{l}\text { Quantidade de } \\
\text { produtos na } \\
\text { Maquina }\end{array}$ & $\begin{array}{l}\text { Qide Demandada } \\
\text { (kg) "Contolado } \\
\text { pelo Arena" }\end{array}$ & $\begin{array}{l}\text { Qtos pallets } \\
\text { precisa? }\end{array}$ & $\begin{array}{l}\text { Qrde Virtual (Kg) } \\
\text { "Contolado pelo } \\
\text { Arena" }\end{array}$ \\
\hline 19 & 1 & Maquina_01 & 1 & 2 & 16,25 & 10 & & 5 & \\
\hline 20 & 2 & Maquina_02 & 1 & 3 & 17,25 & 10 & & 4 & \\
\hline 21 & 3 & Maquina_03 & 1 & 4 & 18.23 & 10 & & 5 & \\
\hline 22 & 4 & Maquina_04 & 1 & 5 & 13.5 & 10 & & 5 & \\
\hline 23 & 5 & Maquina_05 & 1 & 3 & 9 & 10 & & 4 & \\
\hline 24 & 6 & Maquina_06 & 1 & 4 & 10.4 & 10 & & 6 & \\
\hline 25 & 7 & Maquina_07 & 1 & 5 & 23.3 & 10 & & 6 & \\
\hline 26 & 8 & Maquina_08 & 1 & 6 & 14 & 10 & & 6 & \\
\hline 27 & 9 & Maquina_09 & 1 & 1 & 14 & 10 & & 6 & \\
\hline 28 & 10 & Maquina_10 & 1 & 7 & 16 & 10 & & 6 & \\
\hline 29 & 11 & Maquina_11 & & & & & & & \\
\hline 30 & 12 & Maquina_12 & & & & & & & \\
\hline 31 & 13 & Maquina_13 & & & & & & & \\
\hline 32 & 14 & Maquina_14 & & & & & & & \\
\hline 33 & 15 & Maquina_15 & & & & & & & \\
\hline 34 & 16 & Maquina_16 & & & & & & & \\
\hline 35 & 17 & Maquina_17 & & & & & & & \\
\hline 36 & 18 & Maquina_18 & & & & & & & \\
\hline 37 & 19 & Maquina_19 & & & & & & & \\
\hline 38 & 20 & Maquina_20 & & & & & & & \\
\hline 39 & 21 & Verificaçẫo ARENA & 10 & & & & & & \\
\hline
\end{tabular}

Fonte: Autor

A variável indexada "v_maquina" construída em uma planilha do Microsoft Excel é exportada para o modelo de simulação como dados de entrada. Nela o usuário pode ligar ou desligar a quantidade de máquinas de acordo com cada cenário e modificar cada parâmetro de forma individual. Para receber estas matrizes de variáveis, o modelo no software Arena precisa ser ajustado de forma a trabalhar com as variáveis indexadas para que durante a simulação, procure os dados de forma correta e de acordo com a programação das lógicas, modificar estes dados. A Figura 5 mostra as lógicas usadas para o modelo "ler" as variáveis e "gravar" os resultados do arquivo na planilha do Microsoft Excel.

O modelo foi elaborado de acordo com os três setores principais do sistema: Misturadores, Silos Móveis e Embaladoras. 
Figura 5 - Planilha de construção da variável indexada

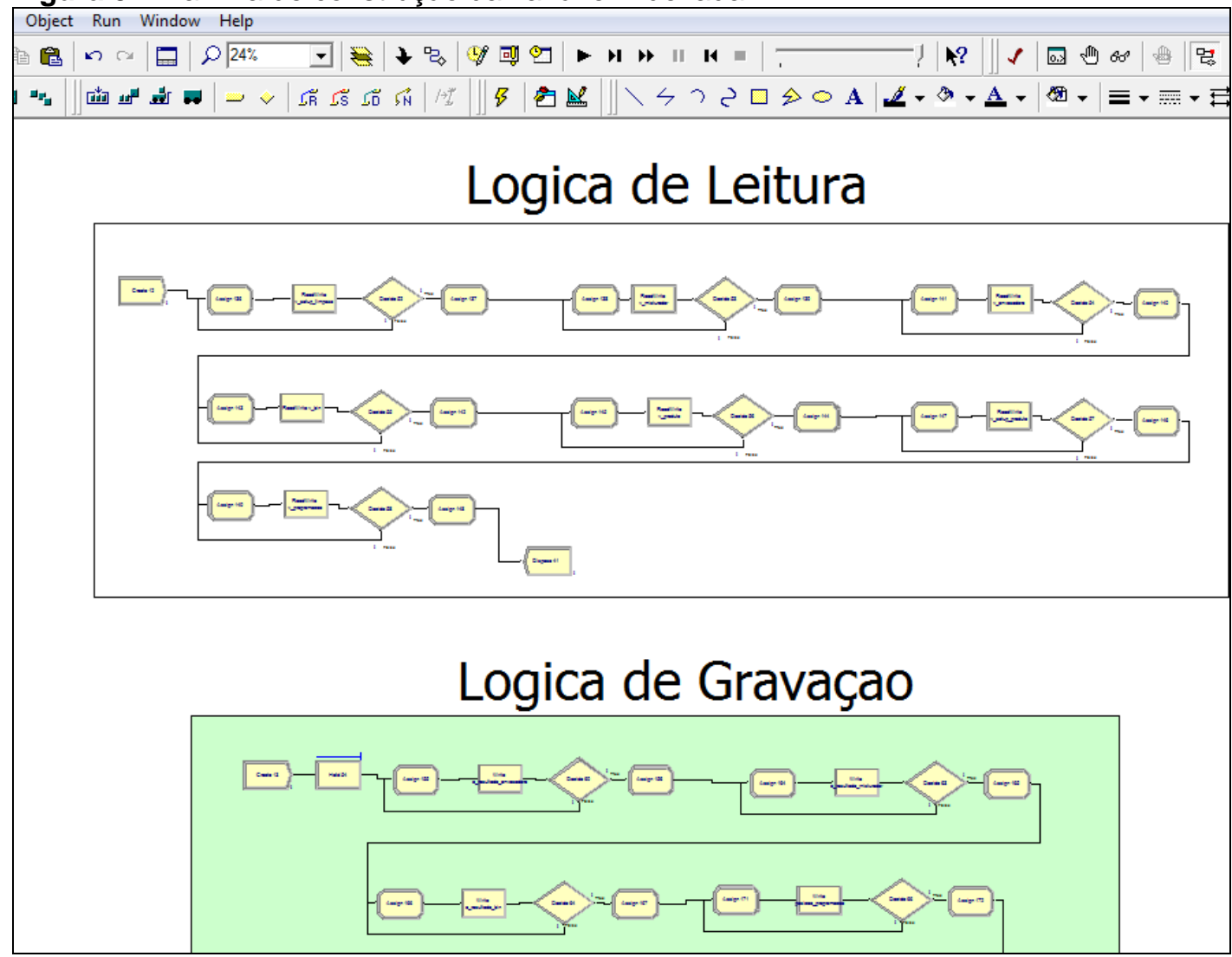

Fonte: Autor

O modelo simula uma semana de planejamento, sendo os produtos a serem produzidos colocados seguindo a ordem que o usuário insere os dados no Excel. $\mathrm{O}$ sistema possui um sistema complexo de escolha de lavagens, pois a cada troca de produto, a máquina respeita uma tabela de lavagem de cada tipo de produto final. De acordo essa tabela para receber um novo produto as máquinas que já foram utilizadas podem necessitar de uma lavagem completa (maior duração), limpeza a seco ou não precisar de limpeza. Após a leitura automática das tabelas preenchidas no Excel, o modelo começa com a lógica de criação das programações, que cria o número de entidades de acordo com o número de produtos e as envia para a lógica de programação onde o modelo escolhe o misturador com menor tempo de limpeza. $\mathrm{Na}$ lógica dos misturadores, enquanto o insumo é misturado, a quantidade de silos móveis é selecionada na lógica dos silos móveis respeitando também o menor tempo de lavagem em relação ao produto que vai ser depositado e envia o produto para a lógica das embaladoras. A Figura 6 mostra as lógicas usadas na estrutura de construção do modelo no software Arena. 
Figura 6 - Estrutura de construção das Lógicas no software Arena

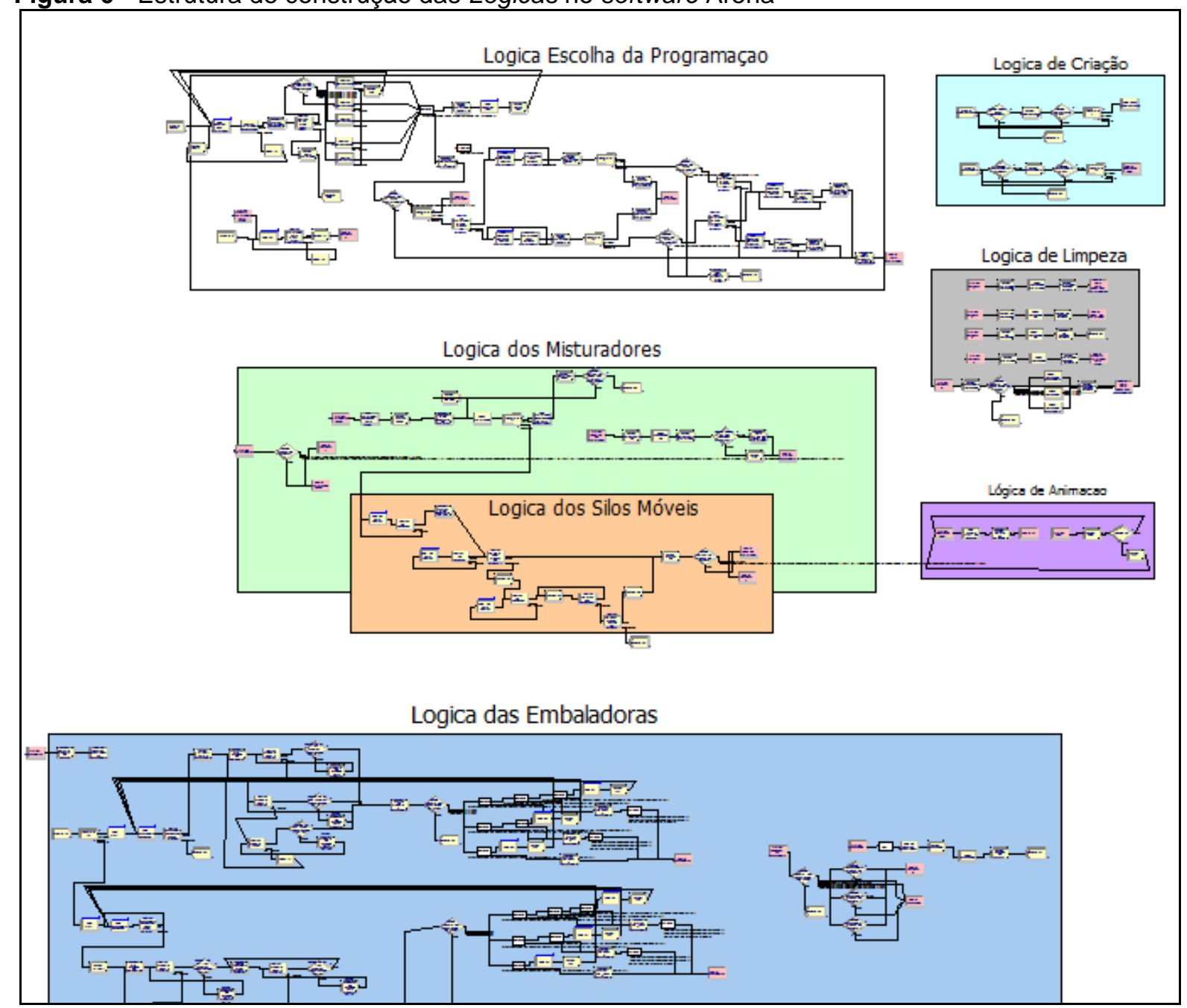

Fonte: Autor

Os mapas do fluxo de valor foram construídos dentro do ambiente de modelagem do simulador Arena e apresentam como proposta a utilização para ambos mapas do MFV. Esta abordagem também permite utilizar as vantagens de um modelo de simulação computacional e dos princípios da filosofia Lean para eliminar desperdícios. A Figura 7 representa todo processo simulado com uma animação construída no modelo com o software Arena. 
Figura 7 - Animação do modelo no software Arena do sistema de produção.

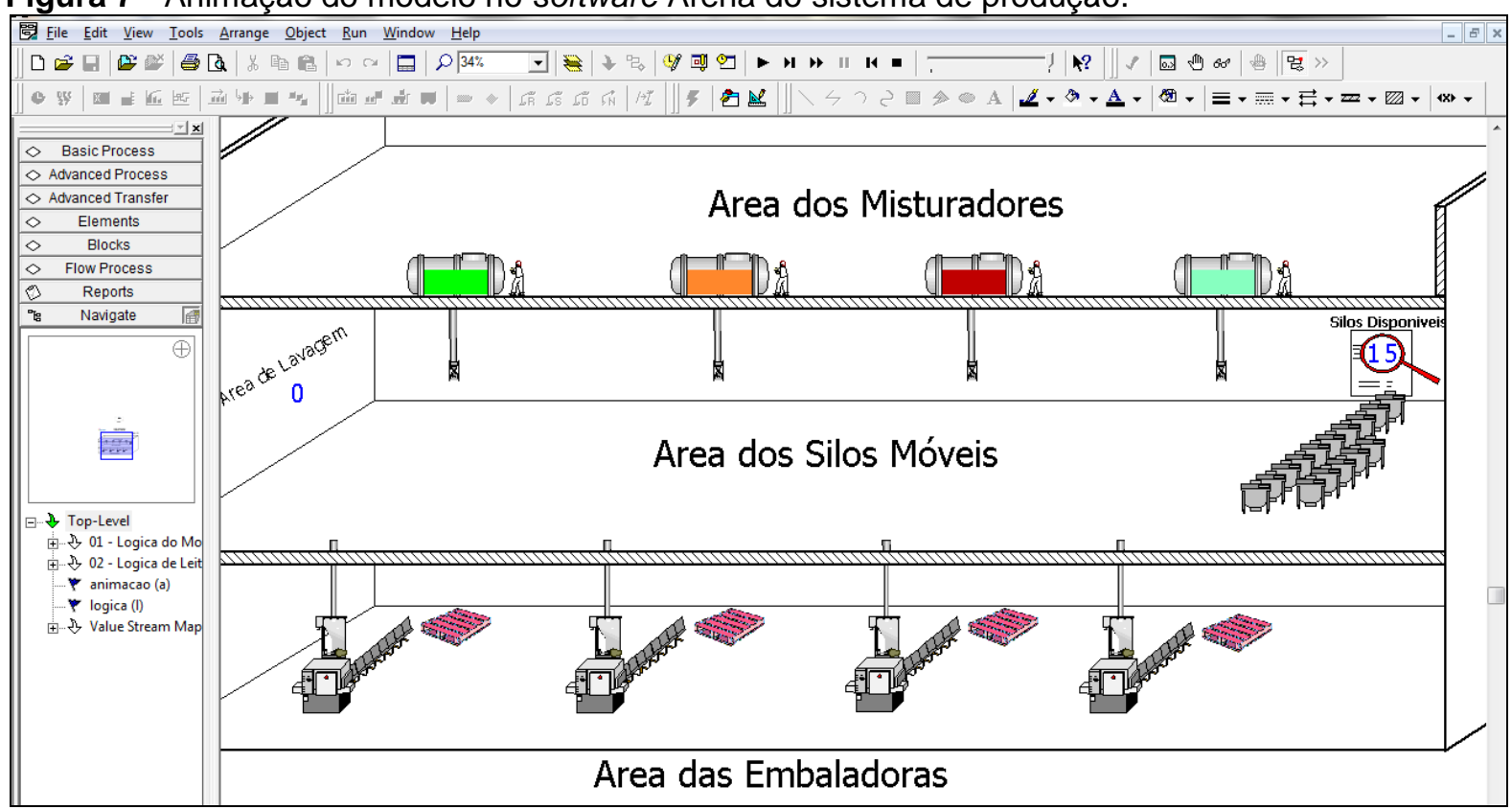

Fonte: Autor

O ambiente computacional Arena possui integração com alguns dos softwares da Microsoft e por esse motivo foi escolhido o Microsoft Visio, que possui as simbologias para construir os mapas do MFV. Os modelos de simulação computacional, em sua construção, mapeiam o processo com alta precisão para permitir seu estudo com fins de validar o atual e prever o comportamento de futuras mudanças. O mapa atual do sistema construído no Microsoft Visio foi elaborado para receber os indicadores do software Arena para depois ser importado para o modelo de simulação. A Figura 8 mostra o mapa atual do sistema, com as observações para o mapa futuro nas caixas de eventos Kaizen e os indicadores dos resultados do cenário atual. 
Figura 8 - Mapa Atual do MFV com os indicadores de resultado.

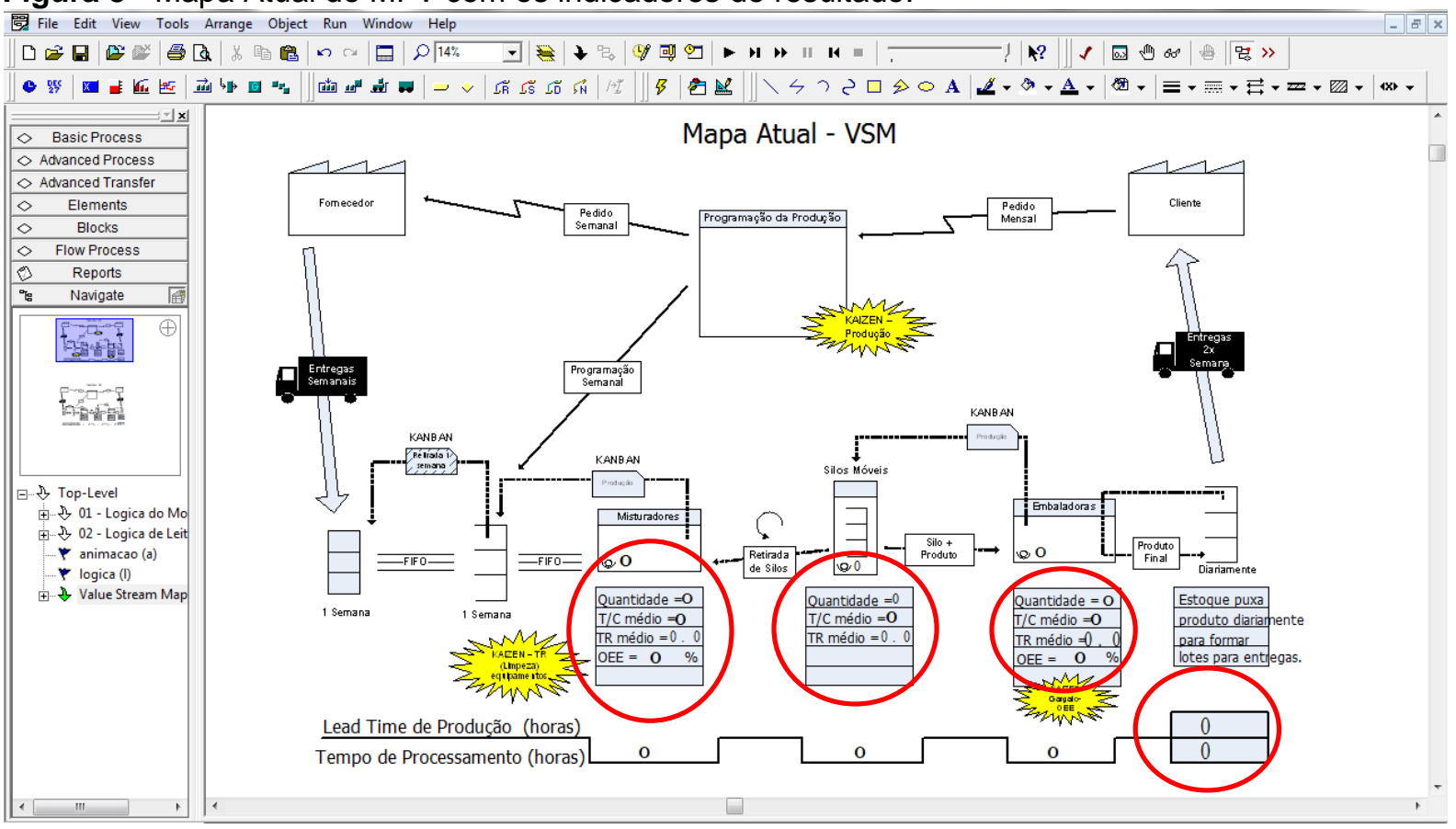

Fonte: Autor

A Tabela 2 mostra o significado dos indicadores de resultado inseridos nos mapas atual e futuro do MFV:

Tabela 2 - Legendas dos indicadores utilizados no mapa atual do MFV.

\begin{tabular}{|l|l|}
\hline \multicolumn{1}{|c|}{ Indicador } & \multicolumn{1}{c|}{ Significado } \\
\hline Quantidade & Quantidade de máquinas no setor. \\
\hline T/C médio (horas) & $\begin{array}{l}\text { Média da soma do tempo de ciclo das máquinas em } \\
\text { relação ao Lead Time de Produção. }\end{array}$ \\
\hline T/R médio (horas) & $\begin{array}{l}\text { Tempo médio de limpeza em relação ao tempo total da } \\
\text { simulação. }\end{array}$ \\
\hline OEE & Overall Efficiency Equipment \\
\hline $\begin{array}{l}\text { Lead Time de } \\
\text { Produção }\end{array}$ & $\begin{array}{l}\text { Tempo total que as máquinas levam para concluir a } \\
\text { produção de todos os produtos e inclui todos os tempos } \\
\text { de processamento, lavagens e transporte. }\end{array}$ \\
\hline $\begin{array}{l}\text { Tempo de } \\
\text { Processamento }\end{array}$ & $\begin{array}{l}\text { Relação entre o Tempo médio de processamento (T/C) } \\
\text { em relação ao Lead Time de Produção. Forma } \\
\text { comparativa na linha do tempo. }\end{array}$ \\
\hline
\end{tabular}

Fonte: Autor 


\section{RESULTADOS}

O modelo de simulação expõe todos os resultados de forma individual para cada máquina, mas para seguir a linha do pensamento enxuto, os resultados das máquinas foram agrupados, tratados como um fluxo e dividido pelos três setores. Com essa divisão, a linha do tempo evidencia o maior tempo de processamento (gargalo) em relação ao Lead Time total da produção utilizado em todos os cenários nos sete dias de simulação. O ideal para a linha de tempo é que os tempos do Lead Time de Produção e o Tempo de Processamento estejam o mais próximo possível que significa menos desperdícios (redução dos processos que não agregam valor). O resultado do tempo de Lead Time de produção abrange todo tempo de processo dos produtos e quanto menor, ou seja, fazer mais com menos recursos. O cenário que representa o sistema atual é composto por quatro Misturadores, quinze Silos Móveis e quatro Embaladoras.

Os resultados deste cenário são representados pela Figura 9 e sua linha do tempo faz a relação do maior tempo produção em relação ao Lead Time total, apontando o gargalo do sistema com sendo o setor de Embalamento.

Figura 9 - Indicadores de resultado inseridos no mapa atual do MFV

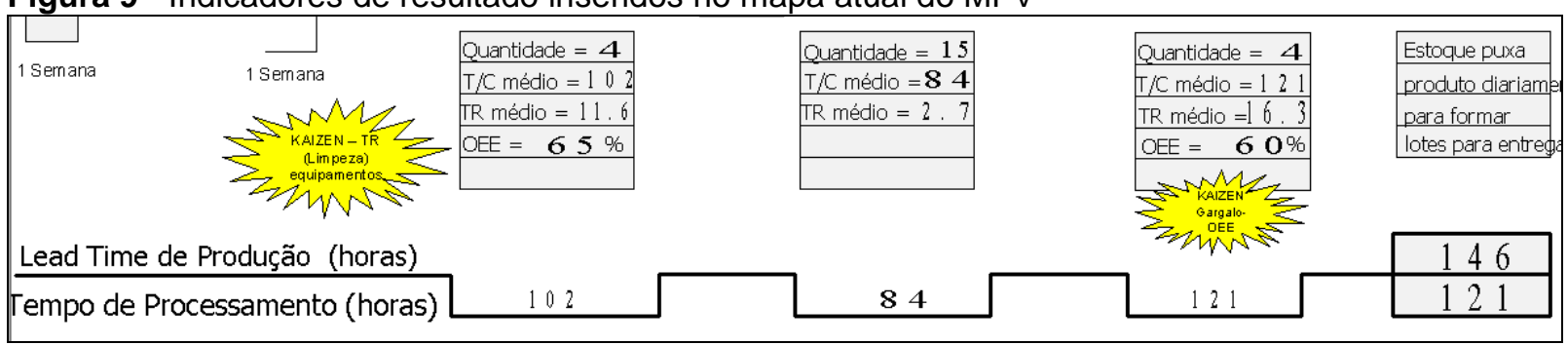

Fonte: Autor

Este cenário expõe o gargalo do sistema, a utilização e tempos de limpeza de cada setor. Os eventos Kaizen foram marcados para construir e validar as melhorias no mapa futuro do MFV e são eles:

i. Adição de critérios para a posição dos produtos no planejamento de produção do simulador;

O modelo de simulação permite que o usuário escolha alguns critérios préprogramados para que o simulador escolha a posição que os produtos entram em produção para reduzir os tempos de limpeza entre as trocas de máquinas. O modelo

Revista Produção Online, Florianópolis, SC, v.14, n. 3, p. 837-861, jul./set. 2014. 
escolhe qual produto entra primeiro na produção para que ocorram menos limpezas durante o período de produção reduzindo o Lead Time de produção.

ii. Redução dos três possíveis tempos de limpeza das máquinas;

Com a redução dos tempos de limpeza, o espaço entre a produção de um produto e outro, diminui.

Melhoria no Overall Efficiency Equipment (OEE) das máquinas de Embalamento.

Como o simulador apontou as máquinas de Embalamento como o gargalo do sistema, a empresa decidiu investir na melhoria do OEE destas máquinas, pois elevaria a eficiência do equipamento diminuindo o tempo de processamento e reduziria o tempo de processo no gargalo, diminuindo o tempo necessário para processar todos os produtos. O tempo de simulação máximo utilizado é sempre de uma semana, podendo acabar antes se todos os produtos forem produzidos.

A Figura 10 mostra o mapa do estado futuro.

Figura 10 - Mapa do estado futuro

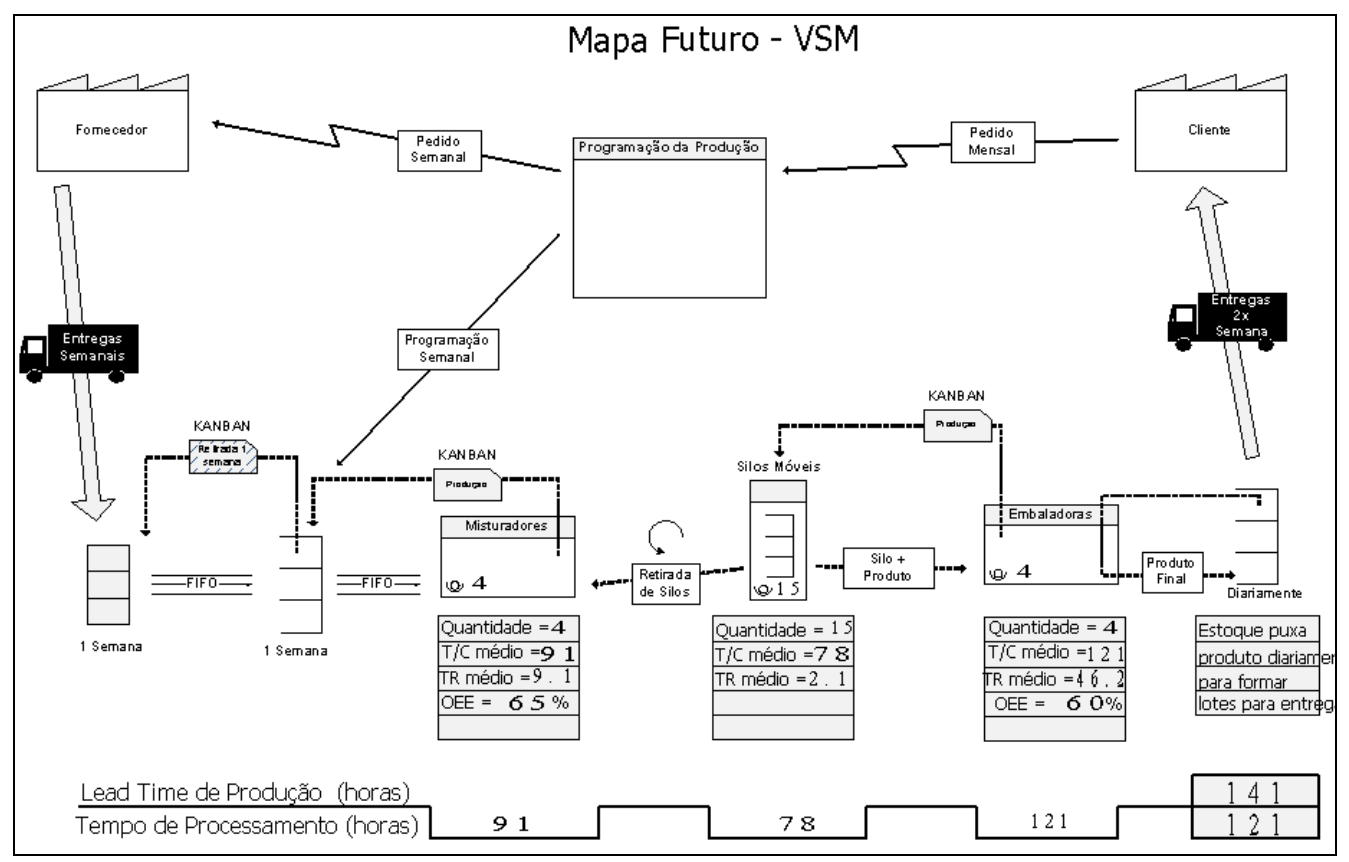

Fonte: Autor

A Figura 11 mostra os detalhes dos indicadores do mapa de valor do estado futuro.

Revista Produção Online, Florianópolis, SC, v.14, n. 3, p. 837-861, jul./set. 2014. 
Figura 11- Indicadores do mapa de valor do estado futuro.

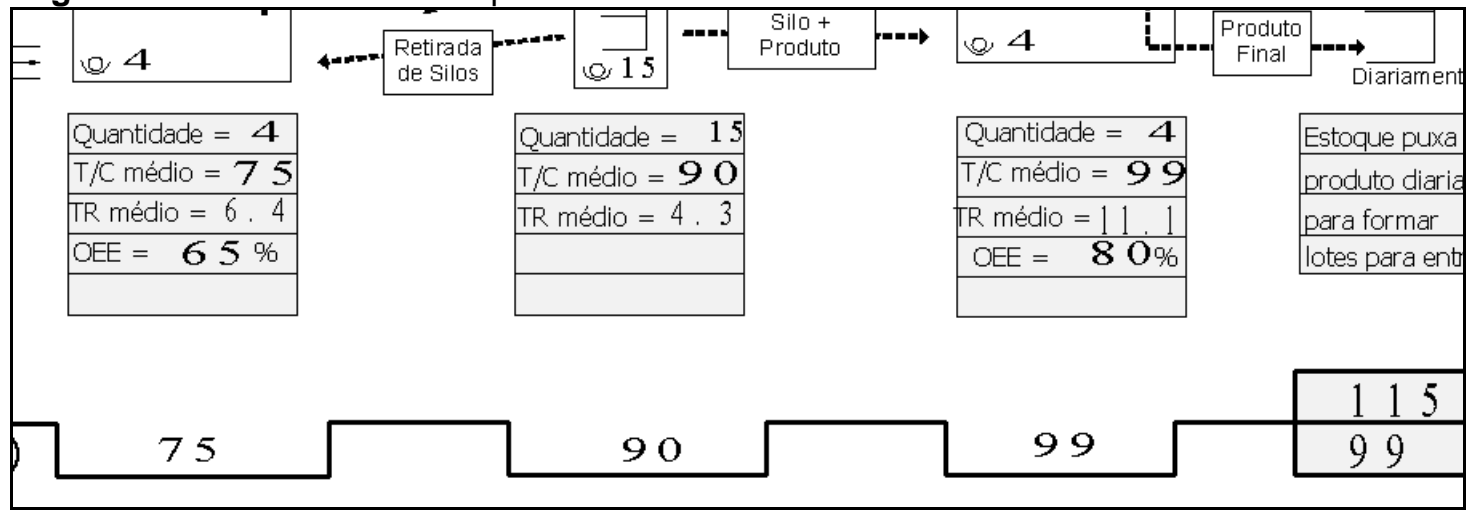

Fonte: Autor

Para testar as melhorias, quatro cenários foram construídos se baseando nos eventos Kaizen:

Futuro 1: Ligar na lógica do modelo os critérios de planejamento da programação para que o simulador encontre a melhor combinação de produtos que reduzam a quantidade de limpezas necessária;

Futuro 2: O tempo das limpezas (limpeza completa e seca) é reduzido em $30 \%$. Para essa redução dos tempos de limpeza, está previsto a implantação de um conceito do pensamento enxuto na manutenção das máquinas, o Total Productive Maintenance - TPM;

Futuro 3: A melhoria do Overall Efficiency Equipment das máquinas gargalo do sistema (Embaladoras) para 80\%.

Futuro 4: O cenário com todos os eventos Kaizen aplicados em conjunto.

Conforme a Tabela 3, do cenário atual para o "Futuro 1", há redução no Lead Time total de Produção com a seleção da melhor posição dos produtos e como consequência, a significativa redução na quantidade de limpeza entre trocas dos produtos nas máquinas. Para o cenário "Futuro 2", a redução de $30 \%$ nos tempos de limpeza impactaram no Lead Time de produção e reduzindo o desperdício de tempo com a limpeza - que não agrega valor.

O cenário "Futuro 3", melhorou para $80 \%$ o OEE fazendo com que o Lead Time total fosse reduzido tornando o processo mais eficiente. A redução no tempo de processamento do gargalo do sistema permitiu que os misturadores trabalhassem com menor tempo de Buffer, alimentando com maior rapidez os silos 
móveis (motivo do aumento em sua utilização), isso reduziu o tempo total de Lead Time da produção.

Com todas as melhorias ativas, o tempo final de Lead Time do processo foi reduzido em mais de $21 \%$, tornando o sistema mais eficiente com a menor diferença entre o Lead Time de produção e o maior tempo de processamento (gargalo) validando os eventos Kaizen para o mapa futuro.

Tabela 3 - Resultados dos cenários do mapa futuro do MFV

\begin{tabular}{|c|c|c|c|c|c|c|}
\hline \multirow[b]{2}{*}{ Cenários } & \multirow[b]{2}{*}{ Setores } & \multicolumn{5}{|c|}{ Indicadores } \\
\hline & & $\begin{array}{c}\mathrm{T} / \mathrm{C} \\
\text { médio }(\mathrm{h})\end{array}$ & $\begin{array}{c}\text { TR } \\
\text { médio }(\mathrm{h})\end{array}$ & $\begin{array}{l}\text { OEE } \\
(\%)\end{array}$ & $\begin{array}{l}\text { Lead Time } \\
\text { de } \\
\text { Produção } \\
\text { (h) }\end{array}$ & $\begin{array}{c}\text { Maior Tempo } \\
\text { de } \\
\text { Processamento } \\
\text { (gargalo) }\end{array}$ \\
\hline \multirow{3}{*}{ Atual } & Misturadores & 102 & 11.6 & 65 & \multirow{3}{*}{146} & \multirow{3}{*}{$\begin{array}{c}121 \text { horas } \\
\text { (Embaladoras) }\end{array}$} \\
\hline & Silos & 84 & 2.7 & - & & \\
\hline & Embalamento & 121 & 20.1 & 60 & & \\
\hline \multirow{3}{*}{ Futuro 1} & Misturadores & 91 & 9.1 & 65 & \multirow{3}{*}{139} & \multirow{3}{*}{$\begin{array}{c}121 \text { horas } \\
\text { (Embaladoras) }\end{array}$} \\
\hline & Silos & 78 & 2.1 & - & & \\
\hline & Embalamento & 121 & 15.3 & 60 & & \\
\hline \multirow{3}{*}{ Futuro 2} & Misturadores & 103 & 8.1 & 65 & \multirow{3}{*}{140} & \multirow{3}{*}{$\begin{array}{c}121 \text { horas } \\
\text { (Embaladoras) }\end{array}$} \\
\hline & Silos & 84 & 1.8 & - & & \\
\hline & Embalamento & 121 & 11.6 & 60 & & \\
\hline \multirow{3}{*}{ Futuro 3} & Misturadores & 85 & 11.6 & 65 & \multirow{3}{*}{122} & \multirow{3}{*}{$\begin{array}{c}99 \text { horas } \\
\text { (Embaladoras) }\end{array}$} \\
\hline & Silos & 90 & 4.1 & - & & \\
\hline & Embalamento & 99 & 15.3 & 80 & & \\
\hline \multirow{3}{*}{ Futuro 4} & Misturadores & 75 & 6.4 & 65 & \multirow{3}{*}{115} & \multirow{3}{*}{$\begin{array}{c}99 \text { horas } \\
\text { (Embaladoras) }\end{array}$} \\
\hline & Silos & 90 & 4.3 & - & & \\
\hline & Embalamento & 99 & 11.1 & 80 & & \\
\hline
\end{tabular}

Fonte: Autor

A simulação permitiu validar os cenários com diversas variáveis e agiu neste projeto como um complemento, validação de investimentos e seguindo as bases do Lean: evitar o Muda - desperdício. Como todo processo possui alguma restrição ou 
gargalo, a simulação visa evitar os desperdícios na implantação de modificações e investimentos e no caso deste processo, o modelo de simulação computacional atuou para testar melhorias construindo cenários futuros do MFV se baseando no mapa atual. O mapa do atual do MFV evidencia os desperdícios e localiza no processo as atividades que agregam valor abrindo oportunidades para eventos Kaizen - onde as possíveis melhorias são localizadas, e serve de base para construir um mapa futuro do MFV do sistema.

Todos os cenários tiveram uma melhora significativa em diversos pontos ou melhorias pontuais, mas no geral, todas as melhoras Kaizen trouxeram algum tipo de melhoria em relação ao cenário real do sistema. Os dados individuais e os mapas futuro mostraram como cada evento Kaizen influencia no sistema e em seu comportamento.

A Tabela 4 faz uma comparação dos indicadores dos mapas futuros do fluxo de valor de todos os cenários que contemplam os eventos Kaizen e a porcentagem de redução do Lead Time em relação ao cenário atual.

Tabela 4 - Tabela com a comparação dos indicadores dos mapas futuros.

\begin{tabular}{|c|c|c|c|c|c|}
\hline Cenários & Setores & $\begin{array}{l}\text { Lead Time } \\
\text { de } \\
\text { Produção } \\
\text { (h) }\end{array}$ & $\begin{array}{c}\text { Tempo de } \\
\text { Processamento } \\
\text { (h) }\end{array}$ & $\begin{array}{l}\text { Lead Time } \\
\text { total da } \\
\text { Simulação(h) }\end{array}$ & $\begin{array}{c}\% \text { de } \\
\text { Redução }\end{array}$ \\
\hline \multirow{3}{*}{ Atual } & Misturadores & 113 & 14 & \multirow{3}{*}{146} & \multirow{3}{*}{0} \\
\hline & Silos & 128 & 10 & & \\
\hline & Embalamento & 140 & 123 & & \\
\hline \multirow{3}{*}{ Futuro 2} & Misturadores & 98 & 14 & \multirow{3}{*}{141} & \multirow{3}{*}{-3.5} \\
\hline & Silos & 122 & 9 & & \\
\hline & Embalamento & 138 & 122 & & \\
\hline \multirow{3}{*}{ Futuro 3} & Misturadores & 110 & 14 & \multirow{3}{*}{139} & \multirow{3}{*}{-5.0} \\
\hline & Silos & 124 & 10 & & \\
\hline & Embalamento & 135 & 123 & & \\
\hline \multirow{3}{*}{ Futuro 4} & Misturadores & 96 & 14 & \multirow{3}{*}{122} & \multirow{3}{*}{-19.7} \\
\hline & Silos & 108 & 10 & & \\
\hline & Embalamento & 116 & 101 & & \\
\hline \multirow{3}{*}{ Futuro 5} & Misturadores & 80 & 14 & \multirow{3}{*}{115} & \multirow{3}{*}{-27.0} \\
\hline & Silos & 100 & 10 & & \\
\hline & Embalamento & 111 & 100 & & \\
\hline
\end{tabular}

Fonte: Autor

Revista Produção Online, Florianópolis, SC, v.14, n. 3, p. 837-861, jul./set. 2014. 
A Figura 12 mostra um gráfico comparativo de acordo com os cenários futuros e o impacto que cada um teve na redução do Lead Time da simulação.

Figura 12 - Gráfico da redução de cada cenário futuro em relação ao Atual.

\section{\% de Redução de Lead Time}

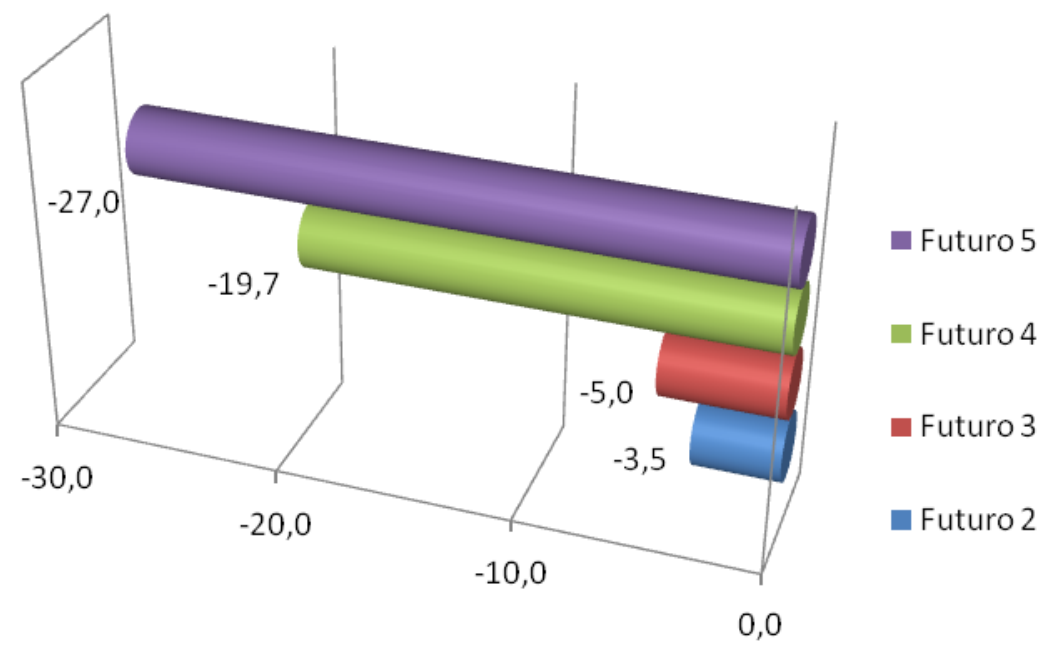

Fonte: Autor

Com todos os eventos Kaizen ativos no modelo de simulação, o tempo final de Lead Time do processo foi reduzido em $-27 \%$, tornando o sistema mais eficiente com a mesma quantidade de recursos iniciais.

\section{CONCLUSÕES}

Foi proposta a utilização da ferramenta MFV juntamente com conceitos da Filosofia Lean em um estudo de caso baseado em dados de um sistema de produção de um produto em pó que tem um processo de embalamento automático. Além de demonstrar completa compatibilidade no uso do software Arena, os mapas do fluxo de valor aumentaram o poder de visualização e juntos, uma melhora significativa no poder de tomada de decisão.

Através da simulação computacional as máquinas gargalo foram identificadas e diversos desperdícios reduzidos com a manipulação de alguns cenários.

A vantagem em usar a simulação em conjunto com os mapas MFV, é conhecer como o cenário atual vai responder às mudanças e validar os eventos 
Kaizen, e ter a possibilidade de prever se a mudança será benéfica e quantifica-la; com isso, construir um cenário futuro ideal plausível e aplicável.

Nas três situações, houve melhorias significativas na visualização dos resultados, e o quarto estado futuro demonstrou o comportamento do sistema com todos os eventos Kaizen aplicados. A aplicação em conjunto do simulador com os mapas de fluxo de valor possibilita ao gestor escolher qual mudança será aplicada em primeiro plano, bem como quando e quais as melhores combinações. Tudo isso com extrema rapidez e assertividade dos resultados, reduzindo riscos.

Para dar continuidade a este trabalho, podem-se recomendar os seguintes aprimoramentos:

- Ampliação dos indicadores dos mapas de fluxo de valor para abranger todos os Lead Times do sistema, desde o a chegada de material até o envio para o cliente e a equivalente modificação no modelo de simulação. Isto possibilitaria um estudo dos desperdícios de movimentação e demais que não agregam valor ao processo permitindo testar novas mudanças.

DIREITOS AUTORAIS: Os autores são os únicos responsáveis pelo conteúdo do material impresso incluído no seu trabalho.

\section{REFERÊNCIAS}

ANAND, G.; KODALL, R. Simulation model for the design of lean manufacturing systems - a case study. International Journal of Productivity and Quality Management, v.4, n.5-6, p. 691-714. 2009 http://dx.doi.org/10.1504/IJPQM.2009.025192

BEKESAS, L.C. Simulação como ferramenta para aplicação do MFV. Dissertação (Mestrado)- Programa de Mestrado em Engenharia de Produção, Universidade Nove de Julho. São Paulo. Brasil. 2012.

CHIAVENATO, I. Administração nos novos tempos. 2. ed. Rio de Janeiro: Elsevier, 2004.

CHOO, C. W. A Organização do Conhecimento. São Paulo: Editora SENAC. São Paulo. 2003. 
FIGUEIREDO, J. C. B. Planejamento orientado por cenários com o uso de modelos causais lineares e diagramas de estoque e fluxo. Revista Produção Online.

Florianópolis, v. 9, n.2, 2009. http://dx.doi.org/10.14488/1676-1901.v9i2.274

DONATELLI, A. e HARRIS, G. Combining Value Stream Mapping and Discrete Event Simulation. In Proceedings of the Huntsville Simulation Conference. By the Society for Modeling and Simulation International, San Diego, CA., 2004.

FIORONI, M. M. Simulação em ciclo fechado de malhas ferroviarias e suas aplicações no brasil: avaliação de alternativas para o direcionamento de composiçoes. São Paulo: USP. Tese (Doutorado), Departamento de Engenharia de Produção. Escola Politécnica da Universidade de São Paulo. 2008.

FREITAS Filho, P. J. Introdução à Modelagem e Simulação de Sistemas com Aplicações em Arena. 2. ed. Florianópolis: Visual Books. 2008.

GAMBI, L. N. Recomendações para a implantação de conceitos e técnicas de produção enxuta em empresas, fabricantes de produtos sob encomenda, do aglomerado industrial de Sertãozinho. 155 f. Dissertação (Mestrado) - Escola de Engenharia de São Carlos, Universidade de São Paulo, São Carlos, 2011.

GONÇALVES, T. J. M.; MADEIRA JUNIOR, A. G.; RIBEIRO, A. C. Avaliação de projeto para implantação de um sistema de voip: um caso na indústria de alimentos. Revista Produção Online. Florianópolis, v.11, n. 3, p. 668-687. 2011. http://dx.doi.org/10.14488/1676-1901.v11i3.545

HARRISON, E. F. Inter-disciplinary models of decision making. Management Decision. v.31, no.8, p. 27-33. 1993. http://dx.doi.org/10.1108/00251749310047124

KELTON, W. D., SADOWSKY, R. P., SADOWSKY, D. A. Simulation with Arena. Ed McGraw-Hill. Boston, Massachusetts, E.U.A. 1998.

KURKIN. O. e SIMON, M.,Optimization of Layout Using Discrete Event Simulation. IBIMA Business Review <http://www.ibimapublishing.com/journals/IBIMABR/ibimabr.html.> 2011. V. Article ID 180343. 10 pages, acesso em 01/07/2013.

LAW, A. M. How to conduct a successful simulation study. Proceedings of the 2003 Winter Simulation Conference. USA. 2003.

LEAN SUMMIT, 2004, São Paulo. Lean Institute Brasil, 2004. Disponível em: < http://www.lean.org.br/leanmail/54/preparacao-do-lean-summit-2004.aspx> e $<$ http://www.lean.org.br/leanmail/53/pos-lean-summit-2004.aspx>. Acesso em 19.09.2012.

MARTINS, J. P. Lógica de programação. Universidade Técnica de Lisboa. Lisboa. 2009. 
MCDONALD T.; VAN AKEN E.M. e RENTES A.F. Utilizing simulation to enhance value stream mapping: a Manufacturing case application. International Journal Of Logistics: Research and Applications, v.5, n. 2, p. 213-232, 2002.

http://dx.doi.org/10.1080/13675560210148696

PEGDEN, C. D.; SHANNON, R.E.; SADOWSKY, R. P. Introduction to Simulation using SIMAN. McGraw-Hill. 2. ed. Nova York. 1995.

PINTO, E. B. Despacho de Caminhões em mineração usando lógica nebulosa, visando ao atendimento simultâneo de políticas excludentes. Dissertação (Mestrado)- Programa de Pós-Graduação em Engenharia de produção, Universidade Federal de Minas Gerais. Belo Horizonte, Brasil. 2007.

QUEVEDO, J. M. G. Modelo de simulação para o processo de carregamento e transporte em mina a céu aberto. Dissertação (Mestrado), Departamento de Engenharia Industrial, Pontifícia Universidade Católica do Rio de Janeiro. Rio de Janeiro. 2009.

ROTHER, M.; SHOOK, J. Learning to See: Value Stream Mapping to Create Value and Eliminate Muda. The Lean Enterprise Institute Broookline. Version 1.2. Massachusetts, USA. 1999.

SILVA, A. K. Método para avaliação e seleção de softwares de simulação de eventos discretos aplicados à análise de sistemas logísticos. Dissertação (Mestrado)- Programa de Pós-Graduação em Engenharia de Sistemas Logísticos, Escola Politécnica da Universidade de São Paulo. São Paulo. Brasil. 2006.

SOLDING, P. e GULLANDER, P., Concepts for simulation based value stream mapping. In Proceedings of the 2009 Winter Simulation Conference, Austin, Texas.

WOMACK, J. P.; JONES, D. T. Lean Thinking - banish waste and create wealth in your corporation. New York: Ed. Simon \& Schuster. 1996.

WOMACK, J. P.; JONES, D. T.; ROOS, D. A máquina que mudou o mundo. Rio de Janeiro: Campus. 1992.

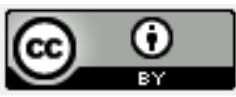

Artigo recebido em 29/09/2012 e aceito para publicação em 22/07/2014 DOI: http://dx.doi.org/ 10.14488/1676-1901.v14i3.1461 